\title{
Comunidade Quilombola Invernada dos Negros e sua relação com o meio natural: um olhar da História Ambiental
}

\section{Quilombola Community Invernada dos Negros and its relationship with the natural environment: a look at Environmental History}

\author{
Samira Peruchi Moretto* \\ Eliane Taffarel ${ }^{* *}$
}

\begin{abstract}
Resumo
A Comunidade Quilombola Invernada dos Negros, situada nos municípios de Campos Novos e Abdon Batista/SC foi assim reconhecida pela Fundação Cultural Palmares em 2004. A comunidade possui características próprias, mas se assemelha a outras em questões como a liberdade e o acesso à terra através de testamento. No Testamento datado de 1877, Matheus José de Souza e Oliveira e Pureza Emilia da Silva, deixaram aos escravizados um terço das terras da fazenda São João, correspondendo a cerca de oito mil hectares de terra composta por campos e matos. 0 território era composto por terras de cultura e de campos de criar sendo a maior parte de matas virgens. Era regularmente ondulado na parte do campo e bastante acidentado nos matos. 0 espaço foi utilizado pelos legatários para a produção e criação de animais. Este artigo visa analisar a relação estabelecida historicamente entre os descendentes dos legatários da Invernada dos Negros com o meio ambiente, a partir da década de 1970. A metodologia utilizada para compreender tais relações foi da História Social, dialogando com a História Ambiental. As alterações no ambiente e no modo de vida da comunidade foram observadas e analisadas através de fontes judiciais e do relatório antropológico produzido pelo Núcleo de Estudos sobre Identidade e Relações Interétnicas (NUER) da Universidade Federal de Santa Catarina (UFSC). A partir das fontes, constatou-se que as alterações no ambiente modificaram a forma como os moradores se relacionavam com o meio natural, assim como se modificou a vida cultural e social da comunidade.
\end{abstract}

Palavras-chave: Comunidade quilombola; Invernada dos Negros; História Ambiental.

\footnotetext{
*Doutora em História. Professora do curso de História e do PPGH da Universidade Federal da Fronteira Sul. E-mail: samira.moretto@uffs.edu.br

${ }^{*}$ Mestre em História pela Universidade Federal da Fronteira Sul. E-mail: elianetaffarel@yahoo.com.br
} 


\begin{abstract}
The Quilombola Community Invernada dos Negros, located in the municipalities of Campos Novos and Abdon Batista / SC was thus recognized by the Fundação Cultural Palmares in 2004. The community has its own characteristics, but resembles others in issues such as freedom and access to land through testament. In the Testament dated of 1877, Matheus José de Souza e Oliveira and Pureza Emilia da Silva left the slaves one-third of the land on the São João farm, corresponding to about eight thousand hectares of land consisting of fields and bushes. The territory consisted of cultivated land and farming fields, mostly virgin forests. It was regularly undulating in the countryside and quite bumpy in the bushes. The space was used by the new owners for the production and breeding of animals. This article aims to analyze the relationship established historically between the descendants of the Invernada dos Negro's legatees, with the environment, from the 1970s. The methodology used to understand such relationships was from Social History, making a dialogue with Environmental History. Changes in the community's environment and way of life were observed and analyzed through judicial sources and the anthropological report produced by the Núcleo de Estudos sobre Identidade e Relações Interétnicas (NUER) da Universidade Federal de Santa Catarina (UFSC). From the sources, it was found that changes in the natural environment changed the way residents related to the natural environment, as well as the cultural and social life of the community.
\end{abstract}

Keywords: Quilombola community; Invernada dos Negros; Environmental History.

\title{
Introdução
}

O dia treze de maio de 1888 é presente nos livros didáticos e na memória popular como o dia da libertação dos escravizados com a assinatura da Lei Áurea pela Princesa Isabel. Porém, por muito tempo a história da escravidão no Brasil não observava as resistências e a participação dos escravizados nesse processo. Também são recentes os estudos do contexto pós-abolição, que buscam compreender as trajetórias dos ex-escravizados, sua mobilidade social e, especialmente, a formação de comunidades negras em todo o país.

A invisibilidade desses grupos se deu por muito tempo na sociedade em geral, mas também na academia. Após o debate realizado pela antropóloga 
Ilka Boaventura Leite, ${ }^{1}$ o Núcleo de Estudos sobre Identidade e Relações Interétnicas da Universidade Federal de Santa Catarina (NUER/UFSC) identificou mais de cem territórios negros nos três estados do Sul do Brasil. Um deles, situado em Campos Novos/Abdon Batista: a Invernada dos Negros. ${ }^{2}$ Dar visibilidade as camadas pobres ou consideradas inferiores, segundo Eric Hobsbawm é um dos preceitos da História Social. Hobsbawm³ afirma também, que para dar uma integralidade a este estudo, é necessário dialogar com outras atividades dos grupos sociais humanos. No presente texto, a comunidade quilombola representa os grupos inferiores e as relações dos mesmos com o meio ambiente e as atividades econômicas, serão factíveis para entendimento do processo de fixação desses grupos no Planalto Catarinense.

A atual comunidade quilombola Invernada dos Negros, reconhecida em 2004 pela Fundação Cultural Palmares, foi formada por escravizados da fazenda São João de propriedade de Matheus José de Souza e Oliveira e sua esposa Pureza Emilia da Silva. Neste espaço, em 20 de janeiro de 1866, os senhores registraram a alforria de seus escravizados, dando a eles uma liberdade condicionada. Além da carta, Matheus e Pureza ratificaram a alforria de alguns libertos, e deram liberdade a outros, em testamento datado de 1877. Neste documento, o senhor ainda deixou a terça parte de suas terras a três libertos (Margarida, Damásia e Joaquim) e oito escravizados (Domingos, Salvador, Manoel, Francisco, Geremias, Pedro, Josepha e Innocência). O Inventário, que iniciou logo após a morte de Matheus, descreve que ele deixava aos mesmos a terça parte de suas terras, em campos de terras lavradias dentro da "Envernada".

Os legatários ${ }^{4}$ fixaram-se na terra, constituindo famílias e permanecendo no território no final do século XIX e ao longo dos séculos XX e XXI.

\footnotetext{
${ }^{1}$ LEITE, Ilka Boaventura. Descendentes de africanos em Santa Catarina: invisibilidade histórica e segregação. In LEITE, Ilka Boaventura (org.). Negros no Sul do Brasil: Invisibilidade e territorialidade. Florianópolis/ SC: Letras Contemporâneas, 1996.

${ }^{2}$ Após anos de permanência na terra, e de resistência, se analisarmos o contexto político, econômico e social
que envolve a mesma, em 1996 o local foi mapeado pelo Núcleo de Estudos sobre Identidade e Relações
Interétnicas da Universidade Federal de Santa Catarina (NUER/UFSC) como um território negro. Diante
do contato com a academia, em 2003, os moradores da comunidade acionaram os pesquisadores através
de uma carta, solicitando auxílio para iniciar o processo a fim de regularizar a questão das terras. Em 20 de
junho de 2004, a Comunidade Invernada dos Negros recebeu da Fundação Cultural Palmares o documento
de Certidão de Auto Reconhecimento como "Comunidade remanescente de quilombos". É nesse ano tam-
bém, que os descendentes dos legatários se reúnem em associação e passam a buscar, além da retomada
das terras, a garantia de direitos básicos como saúde, educação e moradia digna.
} ${ }^{3}$ HOBSBAWM, Eric. Sobre História. São Paulo: Companhia das Letras, 2013, p. 112.

${ }^{4}$ Legatário é aquele para quem alguém deixou algum bem por meio de testamento. Já herdeiro é o que recebe os bens da herança por força da lei. Devido a essa diferenciação jurídica, os ex-escravizados da fazenda São João são chamados de legatários e não de herdeiros. 
Essa trajetória foi marcada por alterações na forma de vida e de interação com o meio natural. As modificações no ambiente da Invernada dos Negros acompanharam as alterações que ocorreram na região. As grandes extensões de terras passaram por reduções já nos primeiros anos do século XX, com o partilhamento das fazendas e a sucessiva divisão entre herdeiros, resultando na redução do tamanho médio das propriedades.

As terras dos legatários estavam situadas no primeiro distrito de Campos Novos, ${ }^{5}$ à margem esquerda do Rio Inferno. A Invernada dos Negros era atravessada por diversos arroios e riachos. O território era composto por terras de cultura e de campos de criar sendo a maior parte de matas virgens. Existiam no terreno várias casas de moradia edificadas pelos proprietários com benfeitorias. Do aspecto físico, o terreno era regularmente ondulado na parte do campo e bastante acidentado nos matos de cultura. A Invernada dos Negros era atravessada de Leste para Oeste por uma estrada de cargueiros e outras estradas vicinais, sendo na parte Leste cortada em parte pela estrada de rodagem que ia da vila de Campos Novos em direção à colônia de Santo Antônio.

Após a década de 1930, se intensifica na região o incentivo à vinda dos novos colonos de origem europeia visando, inclusive pelos governantes de Santa Catarina, o aumento das práticas agrícolas. As florestas também passam a ser vistas como potencial econômico pela extração da madeira, especialmente da araucária. Segundo o governador do Estado de Santa Catarina, General Antônio Vicente Bulcão, em mensagem apresentada à Assembleia Legislativa do Estado, a década de 1930 se mostrava promissora para vinda de imigrantes, uma vez que a crise do café, afugentava-os dos grandes centros:

Já nos chegaram duas levas, no total de 616 pessoas, esperando-se elevar este
número, aproximadamente, a 3500 imigrantes. Também a secretaria da fazenda
está estudando os meios de atrair para o nosso Estado imigrantes húngaros que
se destinam a São Paulo e que por ora não encontram trabalho neste Estado
em consequência da crise do café.

O meio natural era utilizado como propaganda para atrair os imigrantes e migrantes, sendo evidenciado pelas companhias colonizadoras para incentivar a venda dos lotes, mencionando a fertilidade do solo e a presença de

\footnotetext{
${ }^{5}$ As informações estão disponíveis no Memorial descritivo produzido por agrimensores em 1930. O documento traz as confrontações do território e faz descrições que permitem que analisemos a formação do terreno que os ex-escravizados legaram. Está disponível na Folha 66 - Ação de Divisão de Terras - 1928. Arquivo Histórico Dr. Waldemar Rupp de Campos Novos/SC. Tombo: 1278.

${ }^{6}$ Mensagem apresentada a assembleia legislativa, em 22 de julho de 1930, pelo General Antônio Vicente Bulcão Vianna, presidente da mesma Assembleia, no exercício de cargo de Presidente do Estado de Santa Catarina. Acervo: APESC.
} 
pinheiros. No período da colonização, a extração madeireira foi incentivada a fim de dar espaço para as atividades agropecuárias. A extração desses vegetais dependia do contrato estabelecido, pois poderia ser feita pelas próprias companhias colonizadoras ou pelos colonos que compravam os lotes.

Assim, neste artigo, utilizando-se do viés da História Ambiental, buscamos analisar como era formado o meio natural no Planalto Catarinense quando da constituição da fazenda São João; como foi a relação dos negros no pós-abolição com esse meio; e como as ideias da Revolução Verde influenciaram nas mudanças do meio ambiente na Invernada dos Negros.

Donald Worster, ${ }^{7}$ um dos principais autores da história ambiental afirma que esse campo do conhecimento histórico é muito mais inclusivo em suas narrativas, principalmente porque rejeita a ideia de que seja possível ignorar as consequências das ações humanas no meio natural. "A velha história não poderia negar que tivemos neste planeta há muito tempo, mas, por desconsiderar quase sempre esse fato, portou-se como se não tivéssemos sido e não fossemos parte do planeta. Os historiadores ambientais, por outro lado, perceberam que não podemos mais nos dar ao luxo de sermos tão inocentes". ${ }^{8} \mathrm{Ou}$ seja, seu objetivo principal é compreender como os humanos foram afetados pelo ambiente ao longo do tempo, por outro lado, observar também como este afetou o ambiente e com que resultados. Resumindo, a história ambiental visa estudar a interação entre o homem e o meio natural.

Para Worster, há três conjuntos de perguntas que esse campo de pesquisa procura responder, embora elas não necessariamente apareçam no mesmo estudo. Cada uma dessas perguntas exige contribuição de outras disciplinas, somado a métodos especiais de análises.

[...] o primeiro trata do entendimento da natureza propriamente dita, tal como se organizou e funcionou no passado; [...]. O segundo nível da história ambiental introduz o domínio sócio-econômico na medida em que este interage com o meio-ambiente. Aqui nos preocupamos com ferramentas de trabalho, com as relações sociais que brotam desse trabalho, com os diversos modos que os povos criaram de produzir bens a partir de recursos naturais. [...] Por fim, formando um terceiro nível de análise para o historiador, vem aquele tipo de interação mais intangível e exclusivamente humano, puramente mental e intelectual, no qual percepções, valores éticos, leis, mitos e outras estruturas de significação se tornam parte do diálogo de um indivíduo ou de um grupo com a natureza. ${ }^{9}$

\footnotetext{
${ }^{7}$ WORSTER, Donald. Para fazer História Ambiental. Estudos Históricos, Rio de Janeiro, vol. 4, n. 8, 1991, p. 198 - 215. Disponível em http://bibliotecadigital.fgv.br/ojs/index.php/reh/article/view/2324. Acesso em 22 de fevereiro de 2018.

${ }^{8}$ Ibidem, p. 199.

${ }^{9}$ Ibidem, p. 202.
} 
O autor salienta que embora seja possível observar esses três níveis da história ambiental, eles dão conta de uma investigação única e dinâmica. Worster ${ }^{10}$ destaca que natureza, organização social e econômica e pensamento são parte de um todo e assim devem ser tratados. Afinal, quando há mudanças, há transformações nas relações e interações sociais, mas também nas relações e interações com o meio natural.

Pensando nos níveis, quando aplicamos na comunidade quilombola de nosso estudo, o primeiro está relacionado a formação florestal lato sensu. O segundo, será vislumbrado a partir das relações daquele grupo com o meio natural e as atividades econômicas desenvolvidas, por eles. O terceiro, está intrinsecamente ligado com as questões culturais, essenciais para reconhecimento da comunidade quilombola Invernada dos Negros. O viés da história ambiental e a observação da relação dos legatários com a terra possibilitará, portanto, a compreensão da posse atual dos descendentes e os processos de resistência.

Sobre as fontes, José Augusto Drummond ${ }^{11}$ destaca que a História Ambiental permite uma grande quantidade delas e ao mesmo tempo pode utilizar as mesmas fontes que são tradicionais na história econômica ou social.

[....] Nos casos dos povos sem escrita ou da tradição predominantemente oral, os historiadores trabalham com materiais também familiares: mitos e lendas, conforme registrados por viajantes ou antropólogos ou coletados diretamente em trabalho de campo. As boas etnografias antropológicas são riquíssimos repositórios de informes sobre as relações dos povos sem escrita com os seus ambientes naturais. ${ }^{12}$

Nossa principal fonte, nessa área da história ambiental, é o relatório antropológico realizado na comunidade, justamente por conter relatos orais dos descendentes dos legatários.

\section{Planalto Catarinense: formação, usos e alterações}

O meio natural da região do Planalto Catarinense era composto pela Floresta Ombrófila Mista (FOM), termo utilizado atualmente pelo Instituto Brasileiro de Geografia e Estatística (IBGE). De acordo com o IBGE, ${ }^{13}$ esta flo-

\footnotetext{
${ }^{10}$ Ibidem, p. 202.

${ }^{11}$ DRUMMOND, José Augusto. A História Ambiental: temas, fontes e linhas de pesquisa. Estudos Históricos, Rio de Janeiro, vol.4, n.8, 1991, p. 177 - 197. Disponível em http://bibliotecadigital.fgv.br/ojs/ index.php/reh/article/view/2319. Acesso em 22 de fevereiro de 2018.

${ }^{12}$ Ibidem, p. 183.

${ }^{13}$ IBGE. Manual Técnico da Vegetação Brasileira. Rio de Janeiro, 2012. Disponível em https://biblioteca.
} 
resta que ocorria com maior frequência no Planalto Meridional, também é conhecida como "mata-de-araucária" ou "pinheiral".

Marlon Brandt, ${ }^{14}$ citando estudos de Roberto Miguel Klein, relata que a Floresta Ombrófila Mista pode parecer homogênea, se vista de cima, devido a predominância das araucárias. Contudo, esse tipo de floresta possui subformações e submatas com diferentes espécies. Entre as subformações, a floresta dos pinhais (com araucárias de grande porte, com submatas densas) e dos faxinais (com araucárias de menor porte e submata mais baixa). A Floresta de Araucária não é homogênea, mas forma-se de diversas associações e agrupamentos de espécies, que se encontram de forma permanente nos mais variados estágios de sucessão. Entre as espécies que formam a FOM, se destaca o pinheiro (Araucaria angustifólia), o Cedro (Cedrela sp) e a Imbuia (Ocotea porosa).

Nestas formações, há espaços onde as árvores são interrompidas pelos grandes ervais e campos. Essa é a composição da região de Lages, em Santa Catarina, onde Maura Campanili e Miriam Prochnow ${ }^{15}$ descrevem que as árvores da Floresta Ombrófila Mista são intercaladas pelos campos, fato que serviu de atrativo para a pecuária. Esta também é a formação em Campos Novos, onde o espaço era formado por florestas e campos. Sobre eles, as mesmas pesquisadoras relatam que os campos surgiram de forma anterior à Floresta Ombrófila Mista e têm como característica ser uma vegetação de altitudes, podendo ser encontrados a mais de $1.200 \mathrm{~m}$ acima do nível do mar. ${ }^{16}$

O Planalto Catarinense formado, portanto, por campos e florestas, esteve ocupado inicialmente por populações indígenas. Pensando na relação com o meio ambiente, Jackson Peres ${ }^{17}$ afirma que o contato do homem com o meio natural, independentemente do nível, já transforma o mesmo de alguma maneira. Peres destaca a interação das populações indígenas, especialmente Kaingang e Xocleng, relatando que os povos preservavam as araucárias, "pelo

\footnotetext{
ibge.gov.br/visualizacao/livros/liv63011.pdf. Acesso em 15 de maio de 2019.

${ }^{14}$ BRANDT, Marlon. Uma História Ambiental dos Campos do Planalto de Santa Catarina. Tese (Doutorado em História) - Curso de Pós-Graduação em História, Universidade Federal de Santa Catarina, Florianópolis/SC, 2012. Disponível em https://repositorio.ufsc.br/xmlui/handle/123456789/96449. Acesso em 26 de fevereiro de 2018.

${ }^{15}$ CAMPANILI, Maura; PROCHNOW, Miriam. Mata Atlântica: uma rede pela floresta. Brasília: RMA, 2006. ${ }^{16}$ Ibidem, p. 19.

${ }^{17}$ PERES, Jackson Alexsandro. Entre as matas de araucárias: cultura e história Xokleng em Santa Catarina (1850-1914). Dissertação (Mestrado em História) - Curso de Pós-Graduação em História, Universidade Federal de Santa Catarina, Florianópolis/SC, 2009. Disponível em https://repositorio.ufsc. br/xmlui/handle/123456789/92792. Acesso em 17 de outubro de 2018.
} 
grau de importância no fornecimento de alimentos, e pela falta de tecnologia para dar a ela diferentes utilidades". ${ }^{18}$

Com a chegada da ocupação de não-indígenas na região, já ocorrem mudanças no meio natural. Guilherme dos Santos Floriani ${ }^{19}$ destaca que, apesar dos poucos registros sobre o uso das florestas nesse período, é possível afirmar que as mesmas devem ter tido uma grande importância para a fundação do povoado, das fazendas e na viabilização da atividade pecuária.

Sobre essa atividade econômica, Marlon Brandt ${ }^{20}$ destaca que inicialmente a pecuária não gerou grandes transformações no aspecto fisionômico. Isso ocorreu especialmente pelas extensas áreas de campos com eventuais capões e a mata de galeria. Contudo, ele ressalta que isso não quer dizer que não houvessem modificações na natureza. $O$ pesquisador afirma que do século XVIII até o início do XX, as técnicas de criação e manejo dos recursos naturais possibilitaram que os mesmos fossem utilizados sem que se modificassem em grande escala.

Desta forma, se torna perceptível as mudanças nas florestas do Planalto pela derrubada das árvores, especialmente da araucária. Já nos campos, essas alterações são menos perceptíveis. "Elas podem porém ser encontradas pelas alterações promovidas pelo manejo dos animais e plantas, através das queimadas, a introdução de espécies exóticas e o próprio pisoteio e pastejo seletivo dos animais". ${ }^{21}$ Já Floriani ${ }^{22}$ ressalta que as mudanças na vegetação podem ter ocorrido de forma lenta e contínua através da ação dos animais. Ele destaca, por exemplo, a ação do gado quando, no inverno, por carência alimentar, consome uma maior quantidade de plantas do sub-bosque da floresta.

Outra ação que gera transformações se refere ao fato de atear fogo em determinadas épocas do ano, a fim de "limpar" os campos de ervas e possibilitar a brotação do capim que engordava o gado. A queimada era utilizada ainda, a fim de aumentar as áreas de criação do gado. Floriani comenta que a ação da queimada é barata e fácil de ser executada, que expande as fronteiras da

\footnotetext{
${ }^{18}$ Ibidem, p. 98.

${ }^{19}$ FLORIANI, Guilherme dos Santos. História florestal e sócio-lógica do uso do solo na região dos Campos de Lages no Século XX. Dissertação (Mestrado em Manejo do Solo) -Curso de Pós-Graduação em Ciências Agrárias, Universidade do Estado de Santa Catarina - Udesc, Lages/SC, 2007. Disponível em http://www. cav.udesc.br/arquivos/id_submenu/826/guilherme_dos_santos_floriani_joao_fert_neto_29_1.pdf. Acesso em 8 de abril de 2019.

${ }^{20}$ BRANDT, op. cit.

${ }^{21}$ BRANDT, op. cit., p. 84

${ }^{22}$ FLORIANI, op. cit.
} 
pecuária, mas alerta que esse processo, realizado de forma contínua, reduziu de forma gradual a produção da vegetação.

Warren Dean ${ }^{23}$ destaca que a agricultura transformou a relação dos homens com a floresta, cujos solos se percebeu ser mais viável para a produção de alimentos.

Desde o começo, a agricultura na região da Mata Atlântica - de fato em todas as áreas de baixada do continente - exigiu o sacrifício da floresta. A técnica era extremamente simples: perto do fim da estação seca, a macega de uma faixa de floresta - um hectare mais ou menos - era cortada e deixada secar, e, por meio de machados de pedra, retirava-se um anel das cascas dos troncos das árvores maiores. Então, um pouco antes das chegadas das chuvas, a área era queimada, fazendo que a enorme quantidade de nutrientes na biomassa da floresta caísse sobre a terra na forma de cinzas. Algumas das árvores que houvessem resistido ao incêndio permaneciam, chamuscadas mas em pé. As chuvas drenavam os nutrientes para o interior do solo, neutralizando-o e ao mesmo tempo fertilizando-o. Procedia-se então ao plantio, sem qualquer utensílio além de um bastão de cavoucar. A floresta, que nunca antes havia sido queimada, não só ficava maravilhosamente fértil mas também livre das sementes de plantas invasores e, dessa forma, pouca capina era necessária". ${ }^{24}$

Dean ressalta que a queimada era um processo perigoso e problemático, pois exigia que fosse realizada no momento certo em relações as chuvas. Não poderia ser com muita ou pouca antecedência em relação a elas. Essa técnica, conhecida como coivara, era praticada por populações indígenas e, posteriormente, pelas demais etnias. Assim, em maior ou menor proporção, a prática gerou intervenções nas florestas e nos campos do Planalto Catarinense. Essa técnica da queimada para o plantio, a coivara, também era utilizada pelos moradores da Invernada dos Negros. A mesma será destacada mais adiante, junto com a forma de uso do solo na comunidade.

Ainda sobre o Planalto Catarinense, ocorre no início do século XX o processo de "colonização" sendo invisibilizadas todas as ocupações anteriores, formadas por populações tradicionais, como o indígena e o caboclo. "Essa visão é recorrente na expansão ocidental, que desconsiderava toda forma de uso e apropriação da terra que não fosse correspondente ao que se conhecesse como o que seria um uso correto da terra, ou seja, derrubar a floresta, cultivar e criar animais". ${ }^{25}$

\footnotetext{
${ }^{23}$ DEAN, Warren. A ferro e fogo: a história e a devastação da Mata Atlântica brasileira. São Paulo: Companhia da Letras, 1996.

${ }^{24}$ Ibidem, p. 44-45.

${ }^{25}$ BRANDT, op. cit., p. 36.
} 
Diante do objetivo da "modernização", ocorreu em todo o país a ocupação dos "vazios demográficos”. No Planalto Catarinense, a partir dos anos de 1920 o movimento de colonização foi realizado de forma planejada, subvencionada e dirigida pelo governo, por companhias particulares de colonização ou proprietários de maneira individual. Brandt ${ }^{26}$ destaca que o regime republicano absorveu os discursos de que era preciso (re)ocupar o sertão, que era intocado pela "civilização" e onde se encontrava uma natureza "selvagem". De acordo com o pesquisador, esse olhar de que o tempo deveria ser aproveitado para a produção e acumulação de riquezas fez com que as populações locais e tradicionais passassem a ser desqualificadas, assim como o seu ritmo de vida e as técnicas que utilizavam no manejo solo e da natureza. ${ }^{27}$

O incentivo à vinda de colonos iniciada nos anos de 1920 foi se intensificando, assim como as mudanças para as populações tradicionais, seja no Planalto ou no Oeste Catarinense. A antropóloga Arlene Renk, ${ }^{28}$ que estudou a região de Ponte Serrada, no Oeste de Santa Catarina, destaca que a roça cabocla sempre foi apresentada como primitiva, atrasada e praticada em pequena escala.

Esta população adotava uma prática costumeira de dividir as terras em terras de plantar e terras de criar, como eram denominadas. As primeiras situavamse longe de casa, próximas aos cursos d'água. Internamente, a localização distante é apontada como um sinal de abundância de terras. Externamente, esta localização distante era classificada como um método irracional de trabalho, seja pela perda de tempo dispendida no locomover-se, seja como sinal de atraso pela técnica rudimentar empregada (Breves, 1985). "Este método absurdo e atrasado", na acepção de (Breves, 1985), consistia na derrubada de matas, queima e plantio nas cinzas, dada a sua fertilidade. A cada safra este processo era repetido. A parcela anteriormente cultivada era abandonada, transformandose em capoeira. A rotação de terras foi também interpretada como uma forma de não desejarem cercar os animais, deixando-os soltos, nas terras de criar. ${ }^{29}$

\footnotetext{
${ }^{26}$ BRANDT, op. cit.

${ }^{27}$ Nas subformações da Floresta Ombrófila Mista, por exemplo, a população cabocla realizava o corte da erva-mate, plantava para a subsistência e criava animais. Brandt (2012) destaca que esses espaços possibilitaram aos caboclos "o sentimento de localidade, formado através dos laços de parentesco, vizinhança, compadrio, práticas lúdico-religiosas e de entreajuda, como o mutirão” (BRANDT, 2012, p. 157). 0 mesmo autor destaca que o mutirão, também conhecido na região como puxirão, putirão, pixirum ou pixurum, tem como característica a cooperação mútua entre agricultores/produtores. Ocorre entre vizinhos que se ajudam nos trabalhos agrícolas, como a colheita, por exemplo. O puxirão era uma prática de solidariedade existente na Invernada dos Negros. Na pesquisa realizada por Raquel Mombelli e José Bento (2006), eles ouviram pessoas da comunidade que lembravam do mutirão como uma atividade de produção e de trabalho vivenciada no interior do grupo.
}

${ }^{28}$ RENK. Arlene. A luta da erva: um ofício étnico da nação brasileira no oeste catarinense. Chapecó: Argos, 2006.

${ }^{29}$ Ibidem, p. 107-108. 
Renk destaca que além das terras de plantar, que ficavam longe das moradias, existiam as terras de criar. Estas ficavam próximas das casas e eram voltadas aos animais, como galinhas, porcos, bovinos e cavalos. "Internamente, esta modalidade foi vista como 'sistema dos brasileiros' e peculiar a uma época anterior à colonização [...]. Do ponto de vista do colonizador, esta prática foi interpretada como uma incompatibilidade entre os colonos e os caboclos". ${ }^{30}$

Essas diferentes concepções de uso e acesso à terra, associado à apropriação privada da terra e ao adensamento populacional promovido pela colonização, geraram de acordo com Brandt, ${ }^{31}$ tensões entre colonos e caboclos. Um exemplo citado pelo pesquisador é a "invasão dos animais criados à solta nas roças dos colonos". Além disso, nesse período, se instalam na região diversas serrarias, que reduziram, pela derrubada da araucária, a oferta de pinhão aos animais.

$\mathrm{Na}$ Invernada dos Negros, no relatório antropológico realizado por Raquel Mombelli e José Bento, ${ }^{32}$ os pesquisadores afirmam que os descendentes dos legatários registram em sua memória que durante mais de um século de ocupação as terras foram utilizadas na forma de apropriação comum, fazendo uma oposição à forma limitada de uso vivenciada no momento da pesquisa. "Em suas narrativas sobre o passado, apontam a diferença na forma de ocupação afirmando que, 'antigamente as terras da Invernada era tudo do comum"' ${ }^{33}$

De acordo com os pesquisadores, a ideia de apropriação comunal e indivisível está ligada ao que estava previsto no testamento, mas também a forma como os legatários e seus descendentes viviam, seja no aspecto social ou cultural, no passado. Nesse caso, é preciso pensar que essa comunidade negra tem como especificidade o uso da terra associado ao seu passado, ao legado e ao parentesco entre os membros.

Quando se referem ao tempo em que as terras "era tudo do comum", eles estão assinalando uma situação caracterizada pela apropriação comunal de todos os recursos naturais disponíveis. Toda a utilização dos recursos naturais como água, caça, pesca, extração de erva-mate, ou de frutas silvestres era de usufruto comum. Não havia impedimento de nenhuma espécie para que estas

\footnotetext{
${ }^{30}$ Ibidem, p. 108.

${ }^{31}$ BRANDT, op. cit., p. 191.

${ }^{32}$ MOMBELLI, Raquel; BENTO, José. Invernada dos Negros. In Quilombos no Sul do Brasil. Perícias Antropológicas. Florianópolis: Boletim Informativo do NUER, vol. 3 - No 3. 2006.

${ }^{33}$ Ibidem, p. 73.
} 
atividades fossem realizadas por qualquer um dos herdeiros e em qualquer parte da área da Invernada. ${ }^{34}$

É nos relatos orais, registrados por Mombelli e Bento que os membros da Invernada dos Negros comentam a forma de uso das terras legadas. As terras de morar eram destinadas à construção de uma casa ou cabana. Já as terras de plantar se localizavam mais distantes das casas. O trabalho era desenvolvido pela unidade familiar e a preparação da terra levava dias de trabalho intenso.

A preparação da terra para o plantio envolvia diversas etapas, algumas mais demoradas que outras. Um dos primeiros passos consistia na derrubada da mata existente na área a ser lavrada. O mato derrubado era todo queimado. Após esta etapa, iniciava-se a plantação das sementes de milho e feijão, em maior escala, e de abóbora e batata-doce, produtos cultivados até hoje pelo grupo. As árvores circundantes aos limites da área lavrada eram também derrubadas para formar uma espécie de cerca natural. As árvores deitadas garantiam a proteção da plantação contra os animais de criação, geralmente vacas e cavalos soltos pela área. Este processo era repetido enquanto a terra apresentasse condições para a produção de alimentos. Quando a terra começava a apresentar sinais de exaustão, uma nova área era escolhida para ser cultivada..$^{35}$

A produção visava manter os animais de criação e a alimentação da família durante o ano. "Poucos produtos eram comercializados fora da comunidade ou na cidade". ${ }^{36}$ Arlene Renk destaca que a colonização introduziu valores externos na comunidade cabocla, deixando para a mesma apenas duas opções, que era se adaptar ou ser excluída. "[...] A primeira seria a desestruturação do modo de vida anterior à colonização; a segunda, pelo descompasso criado entre o habitus da população e as estruturas econômicas introduzidas pelo colonizador" ${ }^{37}$ A pesquisadora destaca ainda que a colonização é apontada, internamente em Ponte Serrada, onde desenvolveu sua pesquisa, como um divisor de tempos. "O tempo d'antes ou tempo antigo é apresentado como um ‘tempo que não volta mais', por isso é idealizado e apresentado em oposição ao momento presente de penúria, 'estragado"'. ${ }^{38}$ Fato semelhante ocorreu na Invernada dos Negros quando os descendentes dos legatários relatam à Raquel Mombelli e José Bento, ${ }^{39}$ as mudanças na forma de vida da comunidade.

\footnotetext{
${ }^{34}$ Ibidem, p. 73-74.

${ }^{35}$ Ibidem, p. 76.

${ }^{36}$ Ibidem, p. 76.

${ }^{37}$ RENK, op. cit., p. 117-118.

${ }^{38}$ Ibidem, p. 118.

${ }^{39}$ MOMBELLI; BENTO, op. cit.
} 
A "limpeza das terras", iniciava-se expulsando os intrusos, ou seja, os posseiros. Essa "limpeza" destinou as melhores áreas para a venda e empurrou a população posseira para terras de menor qualidade, extremamente acidentadas. De acordo com Renk, a "escassez de área" fez com que chegasse ao fim o binômio terras de plantar/terras de criar. "Da anterior mobilidade, na prática da rotação das roças, das terras de plantar, foi imposta uma imobilidade; da amplidão e espalhamento anterior resultaram o confinamento e a concentração dos brasileiros em áreas acidentadas". ${ }^{40}$

A colonização e o processo de expropriação também estiveram presentes na região do Planalto Catarinense. Na região de campos e florestas, onde era possível cultivar as mais variadas espécies de plantas e criar numerosos animais, Brandt ${ }^{41}$ destaca que o discurso presente era de que se fazia necessário "modernizar" a agricultura e a pecuária. É a partir desse momento que se intensifica na região a ideia de ampliar a produção através da Revolução Verde ${ }^{42}$ e a "modernização" agrícola que intensificarão as modificações do ambiente.

\section{Os "gafanhotos de ferro": a chegada das serrarias}

A profecia de São João Maria ${ }^{43}$ sobre a chegada dos "gafanhotos de ferro" se cumpre quando a extração da madeira se intensifica na região com

\footnotetext{
${ }^{40}$ RENK, op. cit., p. 128.

${ }^{41}$ BRANDT, op. cit.

${ }^{42}$ Sobre a Revolução Verde, Lohn (1997, p. 37-38) destaca que ela "foi um programa internacional que visou desenvolver experiências em genética vegetal, com o fim de criar e multiplicar sementes eficientes, principalmente de trigo, arroz e milho, para diversos solos e climas, bem como resistentes a doenças e pragas, implicando transformações nas tecnologias e práticas de trabalho no campo. 0 discurso dos patrocinadores procurava ressaltar uma imagem humanitária, enfatizando a possibilidade de acabar com a fome no planeta. Apesar disso, o que interessava a muitas corporações eram os lucros que poderiam obter, já que a agricultura estava se tornando um novo campo de valorização para a indústria". Ver: LOHN, Reinaldo Lindolfo. Campos do atraso, campos modernos: discursos da Extensão Rural em Santa Catarina (1956-1975). Dissertação (Mestrado em História) - Curso de Pós-Graduação em História, Universidade Federal de Santa Catarina, Florianópolis/SC, 1997. Disponível em https://repositorio.ufsc. br/xmlui/handle/123456789/77069. Acesso em 13 de março de 2019.

${ }^{43} \mathrm{O}$ território da Invernada dos Negros integrava a região do Contestado, cujo contexto histórico e os conflitos podem ser observados em: MACHADO, Paulo Pinheiro. Lideranças do Contestado. Campinas/ SP: Editora da Unicamp, 2004. O pesquisador relata a presença dos monges na região e a importância dos mesmos, especialmente para a população mais pobre. A devoção a São João Maria deveu-se as curas e poderes sobrenaturais atribuídas a ele. Machado (2004) ainda relata que para João Maria de Jesus o fim da monarquia era o prenúncio de grandes catástrofes que atingiriam o mundo. Assim ele anuncia epidemias; pragas na lavoura e na criação; e a vinda de máquinas monstruosas como corvos de aço (aviões) e gafanhotos de ferro (serrarias), que acabariam com as florestas. No relato dos descendentes dos legatários, o religioso andou pelo município de Campos Novos, sendo assim, também presente a fé no mesmo. Aos pesquisadores Raquel Mombelli e José Bento (2006) eles contaram que o monge teria passado pelas terras, conversado com alguns de seus antepassados e pernoitado próximo ao rio Cambará. Devido a essa passagem do monge, está presente na Invernada dos Negros a memória das profecias. "Uma das mais freqüentes é
} 
a chegada das motosserras. 0 auge da exploração madeireira ocorreu entre os anos 1960 e 1970, e o aumento na extração é justificado, em partes, pela introdução de novas tecnologias que auxiliavam na derrubada das árvores, como a motosserra, por exemplo. ${ }^{44}$ Contudo, até isso ocorrer, Guilherme dos Santos Floriani ${ }^{45}$ destaca que é possível observar na história oficial de ocupação do território e da pecuária que as áreas das florestas tiveram pouco valor econômico e pouca importância social na região. As florestas, segundo o pesquisador, eram habitadas por numerosa população rural que ocupava o território e a utilizava para a subsistência. No entanto, a elite agrária, até então, não a utilizou a fim de alcançar ganhos econômicos.

Floriani relata que na região de Lages, na década de 1940, com o desenvolvimento das pequenas serrarias, a madeira passou a ser utilizada nas benfeitorias rurais. Com a expansão da rede madeireira para o Planalto Catarinense, logo se descobriu o potencial econômico da floresta. No entanto, a exploração capitalista da araucária precisou do desenvolvimento de investimentos que viabilizassem o uso da floresta. Inicialmente a pouca mecanização manteve o nível de produtividade da exploração muito baixa. Contudo, a produção aumentou com a difusão de tecnologias como a "serra americana", e posteriormente, a motosserra. Além disso, as serrarias se tornaram mais rápidas.

\begin{abstract}
A exploração da araucária resultava em grande impacto à floresta remanescente devido ao elevado número de árvores removidas. Chegava-se a remover 150 $\mathrm{m}^{3} / \mathrm{h}$, conhecendo-se volumes superiores a $450 \mathrm{~m}^{3} / \mathrm{ha}$, sem considerar outras espécies madeireiras, permitindo uma rentabilidade bastante elevada com ganhos na escala de extração e industrialização da madeira. Junto deste grande número de pinheiros derrubados sucumbiam um número ainda maior de outras espécies de árvores e cipós. Por isto, a exploração seguia faixas do terreno, ou iniciava pelas árvores distantes, para que a exploração de uma área não dificultasse ou impedisse o acesso às demais. ${ }^{46}$
\end{abstract}

aquela que associam com a condição de ocupação das terras. 'E João Maria falou que a terra iria parecer teia de aranha, que iria ficar como teia de aranha [...]"” (MOMBELLI; BENTO, 2006, p. 64). De acordo com os pesquisadores, a profecia de que a terra viraria "teia de aranha" é traduzida pelos moradores como as cercas que dividem as terras e que olhando atentamente, formam uma grande teia. "Outra profecia do monge muito recorrente é aquela que prevê uma invasão na área de gafanhotos de metal. Na interpretação dos fiéis, os gafanhotos de metal seriam as serras elétricas ou manuais, usadas no corte das árvores e do mato das terras herdadas" (MOMBELLI; BENTO, 2006, p. 64-65).

${ }^{44}$ Ver: NODARI, Eunice Sueli. "Mata Branca”: o uso do machado, do fogo e da motosserra na alteração da paisagem de Santa Catarina. In: NODARI, Eunice Sueli; KLUG, João (orgs). História Ambiental e Migrações. São Leopoldo: Oikos, 2012. P. 35-53.

${ }^{45}$ FLORIANI, op. cit.

${ }^{46}$ FLORIANI, op. cit., p. 86. 
Nesse processo de maior extração madeireira, sua valorização e exportação, Brandt ${ }^{47}$ aponta que o aumento da capacidade dos caminhões para o transporte da madeira e a inserção de motosserras e tratores influenciaram na expansão da devastação das florestas.

O aporte de serrarias na região passou a ser visto com bons olhos pelos pecuaristas locais. A araucária, antes um "problema", passa a ser um aspecto importante na valorização da terra, até então de pouco valor, tornando-se um produto que possibilitava "fazer dinheiro" rápido e fácil, além de expandir a área de criação. Alguns também montaram suas próprias serrarias. ${ }^{48}$

A chegada da indústria madeireira foi percebida também pelos descendentes dos legatários da Invernada dos Negros. Raquel Mombelli e José Bento ${ }^{49}$ destacam que houve a instalação de inúmeras serrarias que afetou diretamente a forma de vida da comunidade. De acordo com os autores, é na década de 1940 que a indústria madeireira se consolida em Campos Novos e região e se torna um dos maiores empregadores da população formada por caboclos e afrodescendentes. Os pesquisadores salientam que o comércio da madeira atinge proporções significativas, sendo rentável até meados da década de 1970 quando a extração da mesma é substituída pela indústria de celulose e papel.

A instalação das serrarias foi ocorrendo até mesmo dentro das terras da Invernada dos Negros. $O$ fato foi relatado pelos moradores à Mombelli e Bento. "Segundo contam os herdeiros 'as serrarias iam chegando e iam se instalando’ em várias regiões das terras da Invernada dos Negros. Algumas foram instaladas próximas as residências dos herdeiros. Outras dentro de seus próprios terrenos". ${ }^{50}$

Os pesquisadores chamam atenção para o patrimônio natural que a extração madeireira destruiu.

A mata de araucárias geralmente aparece associada a uma grande heterogeneidade de espécies, tais como imbuía, cedro, canela e erva-mate, pinheiro-bravo, peroba, e bragatinga. A floresta de araucárias da região é caracterizada por pinhais de grande densidade, agrupados e interrompidos pelos campos. Todo este patrimônio natural foi aos poucos desaparecendo em toda a região, devido a sua exploração descontrolada, passando a ser substituída pelas plantações de pinus e eucaliptos destinados às indústrias de celulose e papel. ${ }^{51}$

\footnotetext{
${ }^{47}$ BRANDT, op. cit.

${ }^{48}$ Ibidem, p. 267.

${ }^{49}$ MOMBELLI; BENTO, op. cit., p. 105.

${ }^{50}$ Ibidem, p. 105.

${ }^{51}$ Ibidem, p. 106.
} 
Na Invernada dos Negros, Mombelli e Bento destacam que na década de 1970 ainda existiam inúmeras araucárias. ${ }^{52}$ Devido ao seu valor comercial, passaram a ser cobiçadas por pessoas externas à comunidade. Os pesquisadores destacam que foi nessa década que ocorreram dois fatores que afetaram diretamente o modo de vida dos descendentes dos legatários: a extração das araucárias e a implementação de pinus e eucalipto, para produção de pasta de celulose.

Sobre a extração das araucárias da comunidade, os moradores relataram a Raquel Mombelli53 que em 1978, pessoas de fora da comunidade dizendo-se advogados, procuraram lideranças do local dizendo que iriam regularizar o restante das áreas legadas.

Diante da possibilidade jurídica de "ajeitar" as terras da Invernada dos Negros, os herdeiros mobilizaram-se e organizaram-se, pois acreditaram que a questão seria resolvida. Esses agentes externos montaram um escritório na casa de um dos descendentes dos herdeiros, residente na cidade de Campos Novos. Nesse local, reúnem documentos pessoais e das terras de vários herdeiros, inclusive daqueles que residiam em outros estados do país. ${ }^{54}$

Outros descendentes dos legatários relataram que motivados pela vontade de "ajeitar as terras", disponibilizaram documentos, assinaram papeis em branco e procurações em nome de terceiros. Contudo, os que se diziam advogados desapareceram, assim como o escritório, a documentação e as fotos tiradas da Invernada através de sobrevoos. "'E de repente, do nada, tudo se sumiu', relatam perplexos os herdeiros diante da situação". ${ }^{55}$

Posteriormente, como resultado desse processo, é elaborado um contrato de compra e venda de árvores de pinheiros araucárias e transforma-se na ferramenta jurídica para justificar a retirada de mais de 80 mil pés (de aproximadamente um metro de espessura), sem que os herdeiros recebessem qualquer tipo de indenização. Conforme o comentário de Dona Nair de Souza: "Eu nunca vi nada, nem dinheiro, nem papel. Nunca recebi um tostão dessa

\footnotetext{
${ }^{52}$ A existência de araucárias na comunidade é referida, entre outras fontes, na Ação de Usucapião impetrada por Domingos Fernandes da Silva em 20 de julho de 1973. Na petição inicial, além da existência de araucárias, o autor relata a forma de uso da terra por esse descendente: plantio e criação. Folhas 2 e 3 da Ação de Usucapião 1975 - de Domingos Fernandes da Silva. Tombo: s/n. Arquivo Histórico Dr. Waldemar Rupp, Campos Novos/SC.

${ }^{53}$ MOMBELLI, Raquel. Visagens e profecias: ecos da territorialidade quilombola. Tese (Doutorado em Antropologia Social) - Curso de Pós-Graduação em Antropologia Social, Universidade Federal de Santa Catarina, Florianópolis/SC, 2009. Disponível em https://repositorio.ufsc.br/bitstream/handle/123456789/93386/275446.pdf?sequence=1. Acesso em 15 de fevereiro de 2016.

${ }^{54}$ Ibidem, p. 140-141.

${ }^{55}$ Ibidem, p. 141.
} 
época. Foi tudo uma enganação" (Nair de Souza). Os pinheiros araucárias foram retirados com a força do trabalho de muitos dos moradores da localidade e, em seu lugar, uma vasta plantação de pinus foi introduzida na região, mudando radicalmente a paisagem do lugar. "Antes da chegada da Firma era tudo pinhal, agora é só pino pra todo lado”, comenta a moradora expressando espanto e indignação. ${ }^{56}$

O processo de substituição das matas de araucária pela plantação de pinus não ocorreu apenas nas terras próximas aos terrenos dos descendentes dos legatários da Invernada dos Negros, mas em todo o Planalto Catarinense.

Floriani ${ }^{57}$ destaca que o esgotamento dos "pinheirais virgens" e a degradação das áreas de floresta remanescentes, aumentou a noção de que não seria possível realizar novos cortes em curto prazo. Esse fato fez surgir a dúvida sobre a continuidade da oferta de madeira.

Antes que o reflorestamento se consolidasse como uma alternativa competitiva de uso do solo no final do século XX havia mais dúvidas do que certezas sobre a viabilidade do plantio de florestas. Em virtude dos fracassos de replantio da araucária não havia viabilidade do reflorestamento naquele contexto, e o plantio do pinus tornava-se mais atrativo, na medida que experiências bem sucedidas se difundiam, mas principalmente a tecnologia e o mercado permitiam a utilização da madeira de pinus. ${ }^{58}$

Luiz Carlos Damian Souto ${ }^{59}$ frisa que os florestamentos com espécies de crescimento rápido são importantes para abastecer o mercado madeireiro e seus derivados "e até mesmo para aliviar a pressão sobre as florestas nativas, que tanto tem se buscado nas últimas décadas. Porém, um segmento não deve inviabilizar o outro, sob pena de criar-se um 'desenvolvimento' sócio-econômico e ecológico desequilibrado ou insustentável”. ${ }^{60}$

Samira Moretto ${ }^{61}$ destaca que a preferência pela espécie exótica para o reflorestamento, em detrimento de espécies nativas, como a araucária,

\footnotetext{
${ }^{56}$ Ibidem, p. 141.

${ }^{57}$ FLORIANI, op. cit.

${ }^{58}$ Ibidem, p. 104.

${ }^{59}$ SOUTO, Luiz Carlos Damian. Florestamento com Pinus spp. e pecuária em campo nativo: complementaridade e concorrência no uso das terras do Planalto Catarinense. Dissertação (Mestrado em Agroecossistemas) - Curso de Pós-Graduação em Agroecossistemas, Universidade Federal de Santa Catarina, Florianópolis/SC, 2005. Disponível em https://repositorio.ufsc.br/handle/123456789/102203. Acesso em 2 de maio de 2019.

${ }^{60} \mathrm{Ibidem}, \mathrm{p} .37$.

${ }^{61}$ MORETTO, Samira Perucchi. Remontando a floresta: A Implementação do Pinus e as Práticas de Reflorestamento na região de Lages (1960 - 1990). Dissertação (Mestrado em História) - Curso de PósGraduação em História, Universidade Federal de Santa Catarina, Florianópolis/SC, 2010. Disponível em https://repositorio.ufsc.br/handle/123456789/93519. Acesso em 28 de novembro de 2017.
} 
deveu-se pelo crescimento mais rápido. A pesquisadora salienta ainda que as primeiras experiências com o Pinus em Lages foram em 1958. Após aperfeiçoamentos e análises de solo, as pesquisas apontaram que o terreno mais propício ao crescimento era nas áreas de florestas recém-devastadas. 0 reflorestamento se intensificou após a aprovação do Código Florestal de 1965, que impulsionou irregularidades e que só foram amenizadas após a aprovação da Constituição de 1988.

Brandt ${ }^{62}$ relata que inicialmente o pinus spp foi visto com desconfiança e desinteresse no Planalto Catarinense, por ser considerada uma madeira fraca e de má qualidade. Contudo, superada essa fase com a ajuda da propaganda e de seu rápido crescimento, somado a escassez da araucária, a espécie se tornou "o centro das atenções". As monoculturas florestais com espécies exóticas, tanto nas áreas florestais quanto nos campos causaram impactos devastadores "que não se resumem ao aspecto fisionômico da paisagem, que é sua maior característica, mas também a total substituição da vegetação nativa, uma vez que as espécies dos Campos são essencialmente heliófilas". ${ }^{63}$

O pinus spp é uma espécie exótica contaminante, que ameaça a biodiversidade. "A 'espécie exótica invasora' é a que ameaça ecossistemas, habitats ou espécies". ${ }^{64}$ Ao ser introduzido no país, o Pinus elliottii foi prejudicial por diversas razões, sendo uma delas a aceleração do esgotamento do solo. "O Pinus elliottii tem suas sementes dispersas pelo vento, anemocóricas, dificultando o controle, propaga suas sementes por centenas e até milhares de metros, podendo ocupar o espaço de outras espécies e não gera alimento para a fauna, o que desequilibra o ecossistema". ${ }^{65}$

Desta forma, o processo de invasão de um ecossistema por uma planta exótica, a contaminação biológica, ocorre quando qualquer espécie não natural de um ecossistema é introduzida nele, e naturalizando-se, passa a se dispersar e a alterar o mesmo. De acordo com Silvia Ziller, ${ }^{66}$ as principais consequências são a perda da biodiversidade, a modificação dos ciclos desse ecossistema e a alteração fisionômica da paisagem natural.

\footnotetext{
${ }^{62}$ BRANDT, op. cit.

${ }^{63}$ Ibidem, p. 274.

${ }^{64}$ MORETTO, op. cit., p. 17-18.

${ }^{65}$ Ibidem, p. 18.

${ }^{66}$ ZILLER, Silvia. Os processos de degradação ambiental originados por plantas exóticas invasoras. Revista Ciência Hoje, São Paulo, 2001. Disponível em http://www.institutohorus.org.br/download/artigos/ Ciencia\%20Hoje.pdf. Acesso em 8 de abril de 2019.
} 
Observando os médios e grandes florestamentos em monoculturas adensadas, Souto ${ }^{67}$ destaca que o manejo nessas áreas, especialmente as que abrangem grandes superfícies, precisa ser melhor entendido pela sociedade, inclusive os produtores de madeiras, a fim de evitar a invasão e/ou a contaminação biológica do bioma e da biota do entorno. O pesquisador destaca que “a 'contaminação biológica' gera grande preocupação, como uma das maiores causadoras de desaparecimento, tanto de espécies animais, como de plantas nativas em todos os continentes, apenas ficando atrás das urbanizações desenfreadas e da agricultura moderna". ${ }^{68}$

As monoculturas arbóreas têm chamado mais atenção do que as de grãos, como a soja, o milho e o arroz. Ele destaca que isso pode ocorrer devido ao aspecto dela ser uma cultura de médio a longo prazo, "ficando por mais tempo às vistas da comunidade em geral, dando a possibilidade para muitas reflexões, diferentemente de monoculturas anuais". ${ }^{69}$ O município de Campos Novos e a região onde se localiza a Invernada dos Negros, foi afetada por diversas monoculturas, como o pinus spp e vários grãos.

\section{A Comunidade Invernada dos Negros: as alterações no ambiente e no modo de vida}

Os descendentes dos legatários da fazenda São João viveram no período pós-abolição sem acesso a direitos básicos como saúde e educação. Ao mesmo tempo, precisaram resistir a fim de permanecer no território, com dificuldades que aumentaram após a colonização e a chegada da "modernização". Essa nova forma de pensar o uso do solo e das florestas afetou profundamente o ambiente e a vida da comunidade.

Para os membros da Invernada dos Negros esse processo de mudança está centrado na imagem da "firma", que é a empresa de Papel e Celulose Iguaçu. A "firma" foi instalada na década de 1970 e alterou a forma de viver dos negros. Segundo Mombelli e Bento, ${ }^{70}$ os descendentes dos legatários estabelecem uma divisão dos dois mundos, do "tempo de antigamente" e do presente, a fim de demarcar o tempo passado como um período de "tempo bom e de fartura que não volta mais, em oposição a um tempo ruim, de escassez e de penúria". ${ }^{71}$ A fartura era demonstrada pela qualidade da terra,

\footnotetext{
${ }^{67}$ SOUTO, op. cit., p. 37.

${ }^{68}$ Ibidem, p. 54.

${ }^{69}$ Ibidem, p. 56.

${ }^{70}$ MOMBELLI; BENTO, op. cit.

${ }^{71}$ Ibidem, p. 81.
} 
já que tudo que plantavam, nascia, mas também pela quantidade de frutas (especialmente o pinhão) e animais disponíveis.

Não conheciam a fome. Caçavam quase todos os bichos que apareciam: cobra, tigre, tamanduá, tatu, etc. O pinhão era tão farto que até mesmo os porcos eram engordados com pinhão, conta um dos moradores. O pinheiro araucária era abundante e suficiente para alimentar as famílias. A madeira, também abundante, era muito utilizada para a construção não só das casas, mas também do cercado para engorda dos animais. A grimpa e o nó de pinho- partes do pinheiro que são retiradas quando secas- eram utilizadas para acender o fogo e assar o pinhão. ${ }^{72}$

Para os moradores da Invernada dos Negros, a chegada da "firma" se torna um momento de descoberta de uma forma de vida diferente, o mato começa a ser derrubado e assim os recursos naturais dos quais os descendentes dos legatários se utilizavam, foram gradativamente desaparecendo.

A terra começou a dar os primeiros sinais de desgaste, pela paulatina substituição da vegetação nativa pela plantação de pinus e eucaliptos. Com o mato derrubado, os animais de caça também desapareceram. Surgiram as cercas e com elas a impossibilidade de usufruir os recursos naturais livremente. 0 gado também já não podia pastar livremente em qualquer área, mas tinha que ser confinado. Como as áreas destinadas para pastos foram reduzidas a possibilidade de manter os rebanhos também ficou comprometida. A impossibilidade de criar o gado solto, uma prática tradicional da Comunidade dos herdeiros, constitui-se, até os dias de hoje, como um foco centralizador e gerador de conflitos com a Firma. As continuidades destas práticas tradicionais são entendidas pela firma, enquanto uma ameaça ao seu sistema de produção, haja vista a constante necessidade de adquirir mais terras para a extração de mata virgem e posteriormente de áreas para o plantio de pinus e eucalipto. Para os membros da comunidade o gado não come e nunca vai comer o pinus, pois não gostam do gosto ruim da árvore. No entanto não conseguem entender porque são tão perseguidos e massacrados ao manterem tal prática. Por várias vezes pudemos observar o guardião do mato,73 pedindo as pessoas para prenderem o gado solto (grifos dos autores). ${ }^{74}$

Os pesquisadores destacam ainda a forma de vida dos descendentes dos legatários, também descrita neste estudo, que era do uso comum das terras, destinando partes para criar, partes para plantar e partes para morar. "Para além destes parâmetros classificatórios nativos, os membros da comunidade da Invernada dos Negros atribuem à terra um significado mítico-histórico.

\footnotetext{
${ }^{72}$ Ibidem, p. 77.

${ }^{73}$ Na pesquisa, Mombelli e Bento (2006) explicam que o "guardião do mato" era geralmente contratado pela empresa a fim de controlar os moradores para que não ocorressem "invasões ou depredações de seu patrimônio".

${ }^{74}$ MOMBELLI; BENTO, op. cit., p. 81-82.
} 
Afinal, o território foi recebido em doação e como dádiva, pra toda vida, deve ser cuidado, protegido e cultuado" (grifo dos autores). ${ }^{75}$ Porém, não foi o que correu com a introdução de exóticas, a monocultura do pinus comprometeu a vida cultural e social da comunidade.

Com efeito, desaparecem as condições ambientais para a realização de práticas tradicionais como o puxerão ou o ajutório, que, preparavam a terra para o plantio construía uma sociabilidade própria. Igualmente, desaparecem as visagens, pois o ambiente degradado interfere nas concepções e práticas locais relacionadas a natureza" (grifo dos autores). ${ }^{76}$

As famílias tiveram, ao longo do tempo, suas áreas de terras reduzidas. Esse fato, somado ao desgaste do solo devido ao intenso plantio de pinus e eucalipto e à falta de assistência técnica, comprometeram a vida dos moradores da Invernada exclusivamente como agricultores, forçando os mesmos a buscar outras formas de sobrevivência. ${ }^{77}$

Assim, além das alterações no ambiente, os pesquisadores destacam que a "firma" criou situações de extrema pressão aos moradores da Invernada dos Negros e explorou os trabalhadores negros, ofertando emprego em condições precárias e com baixos salários.

Como a Firma é uma das únicas alternativas no local para obtenção de uma renda, muitos se sujeitam à situação. Calados, intimidados ou receosos de perder o emprego e de inviabilizar a contratação de outros membros de suas famílias, muitos aceitam as condições desfavoráveis de trabalho. [...] Em inúmeros momentos da pesquisa, pudemos registrar a contestação das práticas de controle e vigilância imposta pela firma à comunidade de herdeiros. [...]. ${ }^{78}$

Na empresa, os pesquisadores destacam que os descendentes dos legatários trabalhavam, até a década de 1970, na plantação e no corte do pinus. No momento do estudo, contudo, além de continuarem envolvidos na atividade, que é terceirizada pela empresa, alguns eram contratados para trabalhar na produção interna, "pois segundo explicam não possuem segundo grau completo". ${ }^{79}$

\footnotetext{
${ }^{75}$ Ibidem, p. 115.

${ }^{76}$ Ibidem, p. 115.

${ }^{77}$ Ibidem, p. 115.

${ }^{78}$ Ibidem, p. 82.

${ }^{79}$ Ibidem, p. 82.
} 


\section{Considerações finais}

O presente artigo analisou as transformações do meio natural, a relação dos habitantes da Invernada dos Negros com o mesmo e como as alterações interferiram no modo de vida dos descendentes dos legatários. Como relata o memorial da Ação de divisão de terras de 1928, a Invernada dos Negros era composta por terras de cultura e de campos de criar sendo a maior parte de matas virgens; o terreno era regularmente ondulado na parte do campo e bastante acidentado nos matos de cultura; e existiam no terreno várias casas de moradia edificadas pelos proprietários com benfeitorias. A fonte demonstra como era o aspecto do meio natural da Invernada dos Negros naquele período e como os negros faziam o uso do solo para a subsistência.

Com a chegada da colonização e da indústria madeireira/celulose, o ambiente da região muda, assim como se modifica na Invernada dos Negros. Percebemos essas alterações e as consequências para a comunidade através do relato dos moradores aos pesquisadores do NUER/UFSC. Durante o final do século XIX e início do século XX, os legatários e seus descendentes plantavam e criavam para a subsistência, fazendo o uso comum do solo. Utilizavam ainda do meio natural para a caça e a coleta, especialmente do pinhão, que servia até mesmo de alimento para os animais.

Com a intensificação da colonização e da ação das indústrias madeireiras, as florestas foram substituídas por plantações de monoculturas. É nesse momento, que os moradores percebem as principais mudanças e relatam a escassez dos recursos naturais, o desgaste do solo e a contaminação da água. Percebemos que as alterações no meio natural modificaram a forma como os moradores se relacionavam com o meio natural, assim como se modificou a vida cultural e social da comunidade.

Artigo recebido para publicação em 04/02/2020 Artigo aprovado para publicação em 19/05/2020 